\title{
Flow and Transport in the Drift Shadow in a Dual-Continuum Model
}

\author{
J. E. Houseworth *, S. Finsterle, and G. S. Bodvarsson \\ Earth Sciences Division, Lawrence Berkeley National Laboratory \\ One Cyclotron Road, Berkeley, CA 94720 USA
}

\begin{abstract}
The current concept for high-level radioactive waste disposal at Yucca Mountain is for the waste to be placed in underground tunnels (or drifts) in the middle of a thick unsaturated zone. Flow modeling and field testing have shown that not all flow encountering a drift will seep into the drift. The underlying reason for the diversion of unsaturated flow around a drift is that capillary forces in the fractures and matrix prevent water entry into the drift unless the capillary pressure in the rock decreases sufficiently to allow for gravity forces to overcome the capillary barrier. As a result of the capillary barrier effect, flow tends to be diverted around the drift, affecting the flow pattern beneath the drift. For some distance beneath the drift, water saturation and flux are reduced. This drift shadow zone is much more pronounced in the fractures than in the matrix due to dominance of gravity over capillary forces in the fractures. Moving downward, away from the drift, the shadow zone asymptotically re-equilibrates to the undisturbed flow conditions due to capillary forces. The behavior of radionuclide transport in this zone of reduced flow is investigated here because this will affect the amount of time required

\footnotetext{
${ }^{*}$ Corresponding author. Fax: +1-510-486-6115; e-mail: JEHouseworth@lbl.gov
} 
for radionuclides to penetrate the unsaturated zone. The delay of radionuclide movement in the geosphere is one aspect of the potential repository system that could limit public exposure to radioactive waste.

The behavior of flow and transport are calculated using a two-dimensional, drift-scale dual permeability model extending to nine drift diameters below the potential waste emplacement drift. The flow model is first compared with an analytical model for a single-continuum. Then the dual-continuum flow model is investigated with respect to drift-scale and mountain-scale property sets. Transport calculations are performed for a wide range of flow conditions and for different aqueous radionuclides and colloids. Findings indicate that transport times for dissolved or colloidal material released from a drift without seepage are several orders of magnitude longer than if the releases occurred in the undisturbed flow field. Furthermore, the calculations indicate that the transport rate for radionuclides released in the drift shadow is relatively insensitive to flow rates in the fractures, but is sensitive to the flow rate in the matrix.

Key Words: Unsaturated zone flow, fractured rock, radionuclide transport, Yucca Mountain, numerical modeling.

\section{Introduction}

\subsection{Hydrogeology at Yucca Mountain}

Yucca Mountain consists of alternating layers of welded and nonwelded volcanic tuffs. The potential repository horizon lies in the unsaturated zone, approximately $300 \mathrm{~m}$ below the ground surface and $300 \mathrm{~m}$ above the water table. This horizon consists of welded tuffs composed of a 
dense porous rock matrix, which is highly fractured. Fracture permeability in the welded tuffs is on the order of darcies $\left(\sim 10^{-12} \mathrm{~m}^{2}\right)$, and the rock matrix permeability is on the order of microdarcies $\left(\sim 10^{-18} \mathrm{~m}^{2}\right)$ (Ahlers and Liu, 2000). Given these rock characteristics and the estimated range of water percolation rates of 1 to $11 \mathrm{~mm} / \mathrm{yr}$ (Wu et al., 2000), most of the water flux in the potential repository host rock is expected to flow in the fractures with a smaller component flowing through the rock matrix. Although most of the flow is in the fractures, approximately $99.8 \%$ of the water volume resides in the rock matrix due to the larger porosity and water saturation in the matrix compared to the fractures.

\subsection{Drift Shadow}

The phenomenon of flow diversion around a cavity was investigated for a homogeneous porous medium by Philip et al. (1989). This diversion of flow was shown to result in flow velocities in a zone beneath the drift that are reduced relative to the undisturbed flow velocities away from the drift. In particular, the flow velocity at the base of the drift is exactly zero. The zone beneath the drift was also found to have lower water saturation than the undisturbed zone. This region of reduced flow velocity and water saturation beneath the drift is known as the drift shadow (Philip et al., 1989).

For a quasi-linear representation of the hydrogeologic properties, Philip et al. (1989) found that the extent of the drift shadow is a function of a characteristic sorptive length scale and the drift radius. The quasi-linear model is a special case in which the logarithm of the relative permeability is linearly proportional to the capillary pressure, where the constant of 
proportionality is equal to 2 divided by the sorptive length scale. The shape of the drift shadow is governed by the ratio of the drift radius to the sorptive length scale. This ratio is a measure of the relative importance of gravitational forces compared with the capillary forces that define flow patterns around the drift. Philip et al. (1989) showed that the drift shadow becomes more elongated (relative to coordinates scaled by the drift radius) as the dimensionless ratio increases (i.e., the gravitational gradient becomes more dominant). Diagrams showing contours of equal flow velocity are given in Philip et al. (1989). Bordering the shadow, near the edge of the drift, a zone of enhanced flow occurs where the diverted flow from the top of the drift is focused.

Capillary effects are much stronger in the matrix than in the fractures in a fractured rock. Based on the results of Philip et al. (1989) the fracture continuum is expected to behave as a gravity-dominated system and the rock matrix as a capillary-dominated system. Therefore, the reduction in flow below the drift is expected to be much more significant for the fracture continuum than for the matrix continuum. Furthermore, the very low water content of the fracture continuum below the drift, due to very low saturation and porosity (as compared with the matrix continuum), means that the vast majority of the water immediately below the drift will be in the rock matrix.

\section{Description of the Flow and Transport Models}

\subsection{Conceptual Model and Numerical Implementation}

The dual-permeability conceptual model is used to simulate flow and transport in a fractured rock. The dual-permeability model allows for flow and transport in a fracture continuum and a 
matrix continuum with advective and diffusive exchange between these continua. The conceptual model for fracture-matrix exchange also incorporates the active fracture model (Liu et al., 1998) in which the fraction of flowing fractures is postulated to be a function of fracture saturation. This type of behavior is a result of flow instabilities caused by adverse mobility ratios in combination with spatially heterogeneous properties, which leads to water flow in only a portion of the connected fracture system. One consequence of the active fracture model is a reduction in fracture-matrix interaction, which is needed to calibrate the dual-permeability flow model to observed matrix water saturations and potentials at Yucca Mountain (Bandurraga and Bodvarsson, 1999). The conceptual flow and transport models are implemented numerically using an integral finite-difference method. Flow calculations are carried out to steady-flow conditions using the TOUGH2 EOS9 module (Pruess et al., 1999), which simulates saturated and unsaturated flow according to Richards' equation. Transport calculations are then performed for steady-state flow conditions using the EOS9nT module of TOUGH2 (Moridis et al., 1999). The transport module first solves Richards equation to establish the steady-state flow field. The solute concentrations are assumed to be sufficiently small such that they have no dynamic effects on the flow (e.g. the density or viscosity). This allows the transport equations to be decoupled from the flow equations. The transport equations are solved using a Laplace transform method applicable to steady-state flow conditions. The Laplace transform method provides a semianalytical treatment of the time derivatives that eliminates the need for time discretization or any restrictions on time-step size. 


\subsection{Numerical Grid and Hydrogeologic Properties}

The calculations presented here are for a two-dimensional, homogeneous, dual-permeability model of an emplacement drift. Figure 1 shows the grid employed in the calculations. The area around the $5 \mathrm{~m}$ diameter drift uses a refined grid of $0.2 \mathrm{~m}$ by $0.2 \mathrm{~m}$. Farther from the drift, the grid coarsens to approximately $2 \mathrm{~m}$ by $2 \mathrm{~m}$. Capillary pressure and relative permeability functions of saturation for the fracture and matrix continua are based on the van Genuchten formulation (van Genuchten, 1980). The property set for the tsw35 hydrogeologic unit (Ahlers and Liu, 2000), which corresponds to the lower lithophysal unit of the Topopah Spring tuff, is used in the flow calculations (see Table 1). This property set is used because about $70 \%$ of the potential waste emplacement areas in the current repository design reside in this unit (McNeish, 2000). The calibrated property set for dual-permeability flow and transport calculations is based on permeability values obtained by calibrating a mountain-scale model against saturation, water potential, and pneumatic pressure data using a large-scale model of Yucca Mountain (Bandurraga and Bodvarsson, 1999; Ahlers et al., 1999). Permeability measured at the drift scale has been found to be roughly one order of magnitude smaller than that inferred from measurements at the mountain scale (Ahlers and Liu, 2000). This difference results from the difference in sampling volume between mountain-scale and drift-scale measurements.

Mountain-scale measurements capture the sparse, but highly permeable, fracture pathways not present in the typical smaller sampling volume. Because of the smaller length scales addressed in this model (tens of meters rather than hundreds of meters), the drift-scale fracture permeability is believed to be more appropriate. For fracture-matrix interaction to be approximately the same for the mountain-scale and drift-scale properties, the drift-scale active fracture parameter, $\gamma$, must 
be increased from 0.41 to 0.81 . An evaluation of the mountain-scale versus drift-scale properties with respect to the active fracture parameter is discussed further below.

An important factor in the drift shadow problem is the diversion of percolation flux around the drift such that water does not enter the drift. A considerable amount of theoretical and experimental work has been conducted to evaluate seepage for the potential waste emplacement drifts at Yucca Mountain (Wang, 2001; Finsterle et al., 2002; Li and Tsang, 2002). This work indicates that the percolation flux encountering a drift will be completely diverted if the percolation flux is less than a value known as the seepage threshold. The seepage threshold depends on the capillary properties of the fracture system, size and shape of the drift, and the heterogeneity in fracture properties.

\subsection{Boundary Conditions}

As shown in Figure 1, the model uses a no-flow symmetry condition along the vertical centerline of the drift. Similarly, the far lateral boundary is a no-flow boundary due to the symmetry condition reflecting the periodic, $81-\mathrm{m}$ drift spacing. The bottom boundary condition is free gravity drainage (no capillary pressure gradient).

The center of the drift is $17.5 \mathrm{~m}$ below the top of the model domain, and the drift has a radius of $2.5 \mathrm{~m}$. Hydrologic properties are assigned to the drift such that the capillary pressure is zero for all values of water saturation. 
Flow is introduced at the top boundary at a prescribed flow rate. For the dual-continuum model calculations, flow rates are prescribed separately for the fracture and matrix continua. This is necessary to develop a flow field compatible with results from the mountain-scale unsaturated zone flow model. The distribution of flow into the fractures and matrix for the 10 $\mathrm{mm} / \mathrm{yr}$ flux (roughly representative of present-day percolation fluxes at the potential repository horizon, $(\mathrm{Wu}, 2000)$ is determined such that the resulting matrix saturations are within the range of observed values, approximately 0.85 to $0.95(\mathrm{Wu}, 2000)$. For higher total percolation rates expected for future climates, $\mathrm{Wu}$ (2000) shows that the percentage of the total percolation moving in the matrix is lower, however the absolute matrix flux increases as expected under wetter climate conditions. Therefore, the percentage of total flux in the matrix is adjusted to allow for more flow in the matrix than found at the lower percolation rates, short of saturating the matrix. Table 2 gives the values of flow rates investigated here. Note the cited fracture flow rate and matrix flow rate in Table 2 and elsewhere in this paper refer to the flow rate maintained at the upper boundary of the model. Because of fracture matrix interaction and flow diversion, the local flow rates at other locations in the model will vary.

\subsection{Transport Parameters}

Transport calculations require the specification of matrix diffusion and sorption parameters. For total system performance assessment, sorption and diffusion parameters have been characterized using a statistical approach to account for the variability found in measured values (Conca, 2000). The parameters used in the calculations reported here have been chosen to be the expected (mean) values used in the site recommendation base case (McNeish, 2000). The driftshadow transport calculations presented here are for technetium, neptunium, plutonium, and two 
sizes of waste form colloids ( $6 \mathrm{~nm}$ and $450 \mathrm{~nm}$ ). These radionuclides were chosen because of their significance in dose calculations for total system performance assessment (McNeish, 2000). The two colloid sizes selected span the expected range of waste-form colloid sizes (Moridis and $\mathrm{Hu}, 2000)$. Under the oxidizing conditions expected in the unsaturated zone, the aqueous form of technetium is the negatively charged pertechnetate ion $\left(\mathrm{TcO}_{4}{ }^{-}\right)$, which is nonsorbing. Under the relevant geochemical conditions, aqueous neptunium has been found to be weakly sorbing to the volcanic rock, and aqueous plutonium has been found to be strongly sorbing. Therefore, the aqueous radionuclides investigated here span the range of expected sorption behavior. Note that sorption is only accounted for in the matrix because values for sorption in the fractures have not been measured and are difficult to estimate. Also, sensitivity studies indicate that sorption in the fractures will only have a significant effect if the sorption coefficients are very large. This is a result of the fact that transport in the fractures is, in general, orders of magnitude faster than matrix transport, therefore sorption in the fractures will only affect travel time if it is strong enough to reduce the transport velocities by orders of magnitude.

Measured values for the effective diffusion coefficients in the matrix are used (Conca, 2000). The effective diffusion coefficient is the product of the diffusion coefficient in water multiplied by the tortuosity. The effective diffusion coefficient for technetium in tuff matrix is found to be smaller than for neptunium or plutonium. This is postulated to be a result of the large size and negative charge of the pertechnetate ion, leading to exclusion from a portion of the matrix pore space (Conca, 2000) and a lower tortuosity. For diffusion in the fractures, the diffusion coefficient in water is adjusted by the tortuosity. The fracture tortuosity is approximated by the porosity (Moridis and $\mathrm{Hu}, 2000$ ). 
The transport of aqueous radionuclides is calculated without including the effects of radioactive decay. For technetium, neptunium, and certain isotopes of plutonium, the half-lives are long relative to the transport times in the drift-shadow model.

The waste-form colloids are clay particles resulting from dissolution of a vitrified waste form. Very little is known about colloid filtration processes in the unsaturated, welded tuffs; therefore, the colloids are assumed to be mobile upon entering the rock. However, size exclusion will limit the fraction of colloids that can enter the rock matrix. As will be seen, transport in the drift shadow is dominated by transport through the matrix. Therefore, the only distinctive property of colloids used here for colloid transport is a reduced diffusion coefficient. Colloid diffusion coefficients are estimated for the fracture and matrix continua using the Stokes-Einstein equation (Moridis and Hu, 2000). The tortuosity for colloids is assumed to be the same as the value found for technetium.

Parameters used for transport are given in Table 3. The active fracture model, which specifies fracture-matrix area and other relevant parameters for fracture-matrix interaction, is also used for defining the corresponding properties needed to compute advective and diffusive exchange between fractures and the matrix. 


\section{Results of Analysis}

\subsection{Consistency with the Philip et al. (1989) Model}

Two calculations were performed for the problem of flow around a drift using a single continuum to compare the results of the Philip et al. (1989) analytical model with the TOUGH2 results. This comparison provides confirmation that the specific implementation of TOUGH2 for flow around a drift is suitable. The analytical model uses the Gardner relationship (Bear, 1972), in which relative permeability is an exponential function of capillary pressure. The TOUGH2 calculations used the Gardner relative permeability function and the van Genuchten capillary-pressure relationship and drift-scale parameters as listed in Table 1. Comparisons were made for two values of the dimensionless capillary coefficient, $s$, in the Gardner (Philip et al., 1989) model. A value of $s$ equal to 0.25 is representative of the matrix continuum, where capillarity dominates gravity. A value of 8 for $s$ corresponds to gravity-dominated flow (Philip et al., 1989), as expected in the fracture continuum. The comparisons were performed using a percolation rate of $10 \mathrm{~mm} / \mathrm{yr}$ for the gravity-dominated system (i.e., the fracture continuum) and $0.32 \mathrm{~mm} / \mathrm{yr}$ for the capillary-dominated system (i.e., the matrix continuum).

Figures $2 \mathrm{a}$ and $2 \mathrm{~b}$ compare vertical flow velocity contours for TOUGH2 and the analytical solution for the cases discussed above. Overall, the agreement between TOUGH2 and the analytical model is very good near the drift and below the drift. Some discrepancies between the solutions are found away from the drift, where grid discretization effects contribute to discrepancies. 


\subsection{Flow Field Results and Parameter Sets}

Unsaturated flow calculations were performed for a dual-continuum model using the mountain-scale and drift-scale property sets shown in Table 1 and the flow rates shown in Table

2. The van Genuchten relative permeability relationship is used for these TOUGH2 calculations. The current repository design locates about $70 \%$ of the emplacement drifts in the tsw 35 hydrogeologic unit (McNeish, 2000). The results of flow calculations using the mountain-scale property set are shown in Figure 3.

The results are qualitatively similar to those found for a single continuum using the Gardner relative permeability model. In particular, the drift shadow is seen to be long and narrow for gravity-dominated fracture flow (Figures $3 b$ and 3d), resulting in a substantial decrease in fracture flow for several drift diameters below the drift. For example, the flow rate within about three drift diameters, on the drift centerline below the emplacement drift, is less than 50 percent of the undisturbed flow rate. The matrix, on the other hand, has a much shorter drift shadow (Figures $3 \mathrm{a}$ and $3 \mathrm{c}$ ), with the flow rate in the matrix less than 50 percent of the undisturbed flow rate within approximately 0.2 drift diameters below the bottom of the drift (Figure 3c).

The original drift-scale property set is the same as the modified drift-scale property set with the exception of the active fracture parameter, $\gamma$. In the original drift-scale property set, $\gamma$ is assigned a value of 0.41 , which is the same as for the mountain-scale property set. The vertical flow and water saturation contours for the original drift-scale property set are shown in Figure 4. However, as shown in this figure, the resulting flow and saturation contours are substantially 
altered for the drift-scale property set. In particular, global vertical gradients of matrix water saturation and flow appear in Figures $4 \mathrm{a}$ and $4 \mathrm{c}$ that contrast with the corresponding plots in Figures $3 \mathrm{a}$ and $3 \mathrm{c}$. The contours in Figure 4 indicate a much greater degree of fracture-matrix interaction than that found for the mountain-scale property set. The flow model calibration against measured values of matrix water potential and saturation was conducted for the mountain-scale property set. Therefore, the original drift-scale property does not appear to be consistent with the field data.

The differences in fracture-matrix interaction found for mountain-scale and drift-scale parameters may be understood from the van Genuchten relationships as modified for the active fracture model. As proposed in Liu et al. (1998), the fraction of active fractures, $f_{a}$, is defined by $f_{a}=S_{e}^{\gamma}$

where $\gamma$ is an empirical parameter of the active fracture model. $S_{e}$ is the effective fracture saturation defined by

$$
S_{e}=\frac{S_{f}-S_{r}}{1-S_{r}}
$$

where $S_{f}$ is the fracture water saturation and $S_{r}$ is the residual fracture water saturation. The active fracture parameter, $\gamma$, is constrained to be less than or equal to one such that the saturation of the active fractures is less than or equal to one. Liu et al. (1998) derive the following relationships for fracture capillary pressure, $P_{c}$, and relative permeability, $k_{r}$, using the van Genuchten formulation (van Genuchten, 1980) in combination with the active fracture concept: 
$P_{c}\left(S_{e}\right)=\frac{1}{\alpha}\left[S_{e}^{(\gamma-1) / m}-1\right]^{1-m}$

$k_{r}\left(S_{e}\right)=S_{e}^{(1+\gamma) / 2}\left[1-\left\{1-S_{e}^{(1-\gamma) / m}\right\}^{m}\right]^{2}$

Figures 3 and 4 show that fracture water saturation is expected to be low, in the range of 0.01 to

0.05. The effective water saturation range is even lower in magnitude. Therefore, it is appropriate to consider an expansion of the capillary pressure and relative permeability functions for low water saturation. The first-order expansions of the capillary pressure and relative permeability functions for low water saturation are,

$P_{c}\left(S_{e}\right) \approx \frac{1}{\alpha} S_{e}^{\left(\frac{1-m}{m}\right)(\gamma-1)}$

$k_{r}\left(S_{e}\right) \approx m^{2} S_{e}^{\frac{4(1-\gamma)+m(1+\gamma)}{2 m}}$

Flux in the fractures, $q_{f}$, can be approximated as free gravity drainage, i.e. the flux in the fractures equals the effective hydraulic conductivity. The effective hydraulic conductivity of the fractures is equal to the product of the saturated hydraulic conductivity, $K_{S}$, times the relative permeability. Using this approximation, the fracture saturation is given by,

$S_{e} \approx\left(\frac{q_{f}}{K_{s} m^{2}}\right)^{\frac{2 m}{4(1-\gamma)+m(1+\gamma)}}$

Substituting this into the equation (5) gives

$P_{c} \approx \frac{1}{\alpha}\left(\frac{K_{s} m^{2}}{q_{f}}\right)^{\frac{2(1-\gamma)(1-m)}{4(1-\gamma)+m(1+\gamma)}}$ 
Note that the exponent of $K_{s}$ is always positive. This relationship shows that for a fixed $q_{f}$, as $K_{s}$ decreases, $P_{c}$ also decreases. This leads to a larger pressure difference between the fractures and matrix and, therefore, greater fracture-to-matrix imbibition flow as $K_{s}$ decreases. This is consistent with the changes in fracture-matrix interaction observed in Figures 3 and 4 using the mountain-scale and drift-scale fracture permeabilities.

The noted increase in fracture-matrix interaction suggests that the fracture-matrix interaction parameter, $\gamma$, needs to be modified for use with the lower drift-scale fracture permeability. Measurements to establish $\gamma$ at the drift scale are not available. However, one of the key calibration metrics used to establish the value of $\gamma$ for the mountain-scale flow model is matrix saturation (Ahlers and Liu, 2000). Figure 5 shows the matrix saturation contours using the driftscale property set over a range of values for $\gamma$. Increasing the value of $\gamma$ reduces fracture-matrix interaction. The matrix water saturation contours for the drift-scale properties with $\gamma$ set to 0.81 (Figure 5d) appear to be consistent with all available data represented by mountain-scale calibration (Figure 5a). Therefore, the modified drift-scale parameter set (Table 1) is believed to be more consistent with field observations.

Calibration of the unsaturated zone flow model (Banduraraga and Bodvarsson, 1999) and comparisons of geochemical composition of perched water (water from the fracture continuum) and matrix pore water (Dixon, 2001) suggest that the fracture and matrix continua are only weakly connected. The unsaturated zone flow model requires severely reduced fracture-matrix interaction areas for calibration against field measurements of water saturation and potential (Ahlers and Liu, 2000). Perched water and matrix pore waters are found to be significantly 
different in composition, indicating a lack of geochemical equilibrium between the fracture and matrix continua. Although the hydrologic and geochemical evidence indicates that the fracture and matrix continua are only weakly coupled, quantitative estimates of parameters reflecting this aspect of the fractured rock system are uncertain. Furthermore, this aspect of the system has a large impact on radionuclide transport in the drift shadow and beyond.

Flow calculations for percolation rates of $10 \mathrm{~mm} / \mathrm{yr}$ and $100 \mathrm{~mm} / \mathrm{yr}$ have been performed and are used in the transport calculations discussed below. Flow behavior for higher total percolation rates also have been investigated. Complete diversion of seepage is found for total percolation rates up to $300 \mathrm{~mm} / \mathrm{yr}$. Between 300 and $350 \mathrm{~mm} / \mathrm{yr}$ total percolation rate, gravitational forces overcome the seepage threshold and water enters the drift.

\subsection{Transport Results}

Transport calculations were run for a dual-permeability flow and transport system using the EOS9nT module of TOUGH2 (Moridis et al., 1999). In all cases, $1 \mathrm{~kg}$ of radionuclides or colloids is available for release from the waste emplacement drift. Connections are made from two cells inside the drift, where the radionuclides and colloids originate, to the fractures and rock matrix cells adjacent to the bottom of the drift and within 1 meter of the drift centerline.

Radionuclides enter the fracture and matrix cells from the drift cells at rates determined by diffusive transport processes, given that water does not flow through the drift cells. 
Breakthrough curves for transport to the bottom of the model (45 $\mathrm{m}$ below the bottom of the emplacement drift, as seen in Figure 1) are shown for technetium, neptunium, plutonium, and two colloids (6 $\mathrm{nm}$ and $450 \mathrm{~nm}$ ) in Figures $6 \mathrm{a}$ through $6 \mathrm{~d}$. These figures compare the transport results for total percolation rates of $10 \mathrm{~mm} / \mathrm{yr}$ and $100 \mathrm{~mm} / \mathrm{yr}$ for two matrix percolation cases each (see Table 2).

A comparison of the $50 \%$ breakthrough with approximate matrix advection-transport times can be made (Table 4). The approximate advection-transport times are computed from the flux introduced to the matrix divided by the approximate water content and retardation factor. The advective transport times are approximate, because flow rates vary as a result of the drift shadow effect and in response to fracture-matrix exchange. Nevertheless, the flow patterns discussed earlier indicate that the variations in flux and water saturation in the matrix are minor. Therefore, the approximate advective transport time is considered reasonable. The retardation factor is given by the relationship

$$
R=1+\frac{\rho_{m}(1-\phi) K_{d}}{\phi S_{w}}
$$

where $\rho_{m}$ is the grain density $\left(2540 \mathrm{~kg} / \mathrm{m}^{3}\right), \varphi$ is the porosity $(0.131), K_{d}$ is the sorption coefficient (see Table 3), and $S_{w}$ is the water saturation (see Table 4). 
In general, the advective travel time in the matrix is close to the value of the $50 \%$ breakthrough time for all percolation fluxes, suggesting that transport in the drift shadow is dominated by matrix advection. Because of the diversion of flow around the drift, radionuclides move from the drift to the rock by diffusion. Diffusive releases preferentially enter the matrix rather than the fractures because the water content (porosity times water saturation) in the matrix is roughly 1000 times larger than in the fractures immediately beneath the drift. In some cases, the $50 \%$ breakthrough time is longer than the advective travel time. This happens for some of the technetium breakthrough curves (such as the case for $10 \mathrm{~mm} / \mathrm{yr}$ total flux with $0.85 \mathrm{~mm} / \mathrm{yr}$ flux in the matrix) because the computed advective travel times in Table 4 ignore the hydrodynamic effects of the drift shadow. In the case of colloids, the $50 \%$ breakthrough time is generally longer than the computed advective travel time because of the hydrodynamic effects as well as the time needed for diffusive release from the waste emplacement drift. For neptunium and plutonium, the $50 \%$ breakthrough times are shorter than the advective travel time because of diffusive exchange between the matrix and the fractures. This occurs for the sorbing radionuclides, which have longer advective travel times and have more time for diffusive release from the matrix to the fractures. Once in the fractures, the travel times are very short.

\subsection{Note on Colloid Transport}

Several aspects of colloid transport are not quantitatively evaluated here due to a lack of information about colloid transport mechanisms. On Figures $6 \mathrm{a}-\mathrm{d}$, an estimate of the fraction of colloids that cannot enter the matrix is given for both $6 \mathrm{~nm}$ and $450 \mathrm{~nm}$ colloids. This estimate is based on the fraction of pore sizes larger than the colloid size as interpreted from capillary pressure curves (McGraw, 2000). This screening fraction only addresses the initial entry into the 
matrix. For the drift shadow transport problem, colloids must transport tens of meters through the matrix to arrive at the bottom boundary of the model. The more extensive contact between colloids and the matrix leads to a higher probability for trapping colloids by size exclusion, as colloids migrate through a series of pore throat constrictions. Therefore, an even greater fraction of colloids are likely to be retained in the matrix near potential waste emplacement drifts.

\subsection{Transport Sensitivity Analysis}

The behavior of transport in the drift shadow is shown in Figures 7a through 7d, which show the concentration and flux for technetium 2535 years after release in the drift for both the fracture and matrix continua. The concentration and flux contours in the matrix are very similar, indicative of a relatively simple advective transport process. However, the concentration and flux contours in the fractures are quite different from each other. The fracture concentration contours peak near the drift, lagging both the peak flux contour in the fractures and the concentration and peak flux contours in the matrix. The peak concentration in the fractures occurs close to the drift where fracture flow rates are low, resulting in large concentrations, despite small matrix to fracture diffusion rates. The peak flux in the fractures leads the peak flux in the matrix, but is considerably smaller in magnitude. The peak flux in the fractures is also offset from the drift centerline, unlike the matrix peak flux and peak concentration contours. The fracture flux contours are strongly influenced by the matrix concentration, fracture water saturation, and fracture flow rate. The fracture water saturation and matrix concentrations influence the rate of diffusive transfer between the fractures and the matrix, and the fracture flow rate affects radionuclide flux. The peak flux is the point at which the combination of these factors is maximum. The fracture water saturation and flow rate are smallest along the centerline 
as a function of horizontal position. This leads to the offset in the fracture peak flux contour from the drift centerline. These profile results support the conceptual picture that transport is occurring primarily in the matrix and that matrix-to-fracture diffusion is an important factor for technetium flux in the fractures.

Figure 8 compares breakthrough curves for technetium under different total percolation flux and matrix flux cases. The breakthrough curve sensitivity to total percolation flux is found to be low, with much greater sensitivity to the rate of percolation flux in the matrix. This result further substantiates the concept that transport in the drift shadow is predominantly in the matrix.

Figures $9 \mathrm{a}$ and $9 \mathrm{~b}$ compare transport in the drift shadow to transport in the unperturbed flow field for $10 \mathrm{~mm} / \mathrm{yr}$ and $100 \mathrm{~mm} / \mathrm{yr}$ total percolation fluxes. The releases in the unperturbed flow field were made in cells near the right-hand boundary of the model at the same vertical coordinate as the bottom of the drift. Two types of releases were investigated; releases that are initiated in the fractures and releases that are initiated in the matrix. The drift shadow breakthrough curve is shown for comparison. The results clearly demonstrate that releases to the fractures transport at much greater velocities. These results also demonstrate that the drift shadow effect is primarily caused by initiation of transport in the matrix. The dynamics of the drift-shadow flow field have only a second-order effect on the breakthrough curves.

Figure 10 shows a sensitivity calculation for the effects of the active fracture parameter, $\gamma$, on breakthrough curves. This figure clearly shows that fracture-matrix interaction is a key factor in 
the rate of transport in the drift shadow. As $\gamma$ is reduced, the amount of fracture-matrix interaction increases, resulting in greater matrix-to-fracture diffusive exchange. Increased interaction results in more transport in the fractures and, therefore, more rapid transport through the drift shadow.

\section{Conclusions}

The diversion of percolating water around a potential waste emplacement drift results in a non-flowing environment inside the drift. In such an environment, the only transport mechanism for radionuclides to migrate from the drift to the surrounding rock is by diffusion. Because of the relatively large amount of water in the matrix in comparison with the fractures, diffusive releases are highly partitioned to the matrix. The transport time for radionuclides initiated in the matrix has been found to be orders of magnitude longer than for radionuclides initiated in undisturbed fracture. Note that the breakthrough curves presented here are for a boundary $45 \mathrm{~m}$ below the potential repository, whereas the water table is an average of about $300 \mathrm{~m}$ below the potential repository (DOE, 2001, Section 4.3.3.1). The average (or 50\%) breakthrough times are dominated by matrix advection. Simulation results show that for these cases, most of the radionuclide mass still remains in the matrix at breakthrough. Therefore, the effects of the drift shadow on transport extend beyond the existing model boundary. For radionuclide releases from drifts without seepage, the results presented in this section indicate that transport times to the water table will be thousands to tens of thousands of years for non-sorbing radionuclides such as technetium. For sorbing radionuclides, the transport times are considerably longer according to the degree of sorption. For a weakly sorbing radionuclide such as neptunium, the transport times are tens of thousands of years to hundreds of thousands of years. For a strongly sorbing 
radionuclide such as plutonium, the transport times range from millions to tens of millions of years. Colloids have been shown to have transport times somewhat longer (by $5 \%$ to $20 \%$ ) than for technetium, ignoring all colloid filtration mechanisms. However, size exclusion is expected to strain $35 \%$ to $95 \%$ of the colloids at the drift boundary and the long transport pathways (tens of meters) through the matrix is expected to filter most of the remaining mobile colloids.

Sensitivity calculations show that the main effect of the drift shadow on transport is that radionuclide transport is initiated in the matrix. Subsequent effects of the drift shadow on the dynamics of the fracture or matrix flow fields have much less influence on transport. The long transport pathways in the matrix are primarily due to initiation of transport in the matrix combined with the relatively "disconnected" nature of the fracture and matrix continua. Varying degrees of fracture-matrix interaction in the dual-permeability model are shown to have a significant influence on transport in the drift shadow.

\section{Acknowledgments}

The authors appreciate the technical review of this paper by Chin-Fu Tsang. This work was supported by the Director, Office of Civilian Radioactive Waste Management, U.S. Department of Energy, through Memorandum Purchase Order EA9013MC5X between Bechtel SAIC Company, LLC and the Ernest Orlando Lawrence Berkeley National Laboratory (Berkeley Lab). The support is provided to Berkeley Lab through the U.S. Department of Energy Contract No. DE-AC03-76SF00098. 


\section{REFERENCES}

Ahlers, C. F., Finsterle, S., and Bodvarsson, G. S., 1999. Characterization and prediction of subsurface pneumatic response at Yucca Mountain, Nevada. Journal of Contaminant Hydrology 38(1-3): 47-68.

Ahlers, C. F. and Liu, H. H., 2000. Calibrated Properties Model. MDL-NBS-HS-000003 REV

00. CRWMS M\&O, Las Vegas, Nevada.

Bandurraga, T. M., and Bodvarsson, G. S., 1999. Calibrating hydrogeologic parameters for the 3D site-scale unsaturated zone model of Yucca Mountain, Nevada. Journal of Contaminant Hydrology 38(1-3), 25-46.

Bear, J. 1972. Dynamics of Fluids in Porous Media. American Elsevier Publishing Company, Inc., New York, New York.

Conca, J., 2000. Unsaturated Zone and Saturated Zone Transport Properties (U0100). ANLNBS-HS-000019 REV 00, ICN 01. CRWMS M\&O, Las Vegas, Nevada.

DOE 2001. 0539 Yucca Mountain Science and Engineering Report, DOE/RW-0539. Las Vegas, Nevada. 
Dixon, P. R., 2001. Analysis of Geochemical Data for the Unsaturated Zone. ANL-NBS-HS000017 REV 00 ICN 01. Bechtel SAIC Company, Las Vegas, Nevada.

Finsterle, S., Ahlers, C. F., Trautz, R. C., and Cook, P. J., 2002. Inverse and Predictive Modeling of Seepage into Underground Openings. Journal of Contam. Hydrol., this issue.

Li, G., Tsang, C-F., 2002. Seepage into Drifts with Mechanical Degradation. Journal of Contaminant Hydrology., this issue.

Liu, H. H., Doughty, C., Bodvarsson, G. S., 1998. An Active Fracture Model for Unsaturated Flow and Transport in Fractured Rocks. Water Resources Research,. 34(10): 2633-2646.

McGraw, M., 2000. UZ Colloid Transport Model, ANL-NBS-HS-000028, REV 00, CRWMS M\&O, Las Vegas, Nevada.

McNeish, J. A., 2000., Total System Performance Assessment for the Site Recommendation, TDR-WIS-PA-000001, REV 00, ICN 01. TDR-WIS-PA-000001. CRWMS M\&O, Las Vegas, Nevada.

Moridis, G. and Hu, Q., 2000. Radionuclide Transport Models Under Ambient Conditions. MDL-NBS-HS-000008, REV 00, CRWMS M\&O, Las Vegas, Nevada. 
Moridis, G., Wu, Y.-S., and Pruess, K., 1999. EOS9nT:A TOUGH2 Module for the Simulation of Water Flow and Solute/Colloid Transport in the Subsurface, Report LBNL-42351, Lawrence Berkeley National Laboratory, Berkeley, Calif.

Philip, J. R., Knight, J. H., and Waechter, R. T., 1989. Unsaturated Seepage and Subterranean Holes: Conspectus, and Exclusion Problem for Circular Cylindrical Cavities. Water Resources Research, 25(1): 16-28.

Pruess, K., Oldenburg, C., and Moridis, G., 1999. TOUGH2 User's Guide, Version 2.0, Report LBNL-43134, Lawrence Berkeley National Laboratory, Berkeley, Calif.

van Genuchten, M. Th., 1980. A Closed-form Equation for Predicting the Hydraulic Conductivity of Unsaturated Soils. Soil Science Society of America Journal, 44(5): 892-898.

Wang, J. S. Y., andBodvarsson, G.S., 2002. Evolution of the Unsaturated Zone Testing at Yucca Mountain. Journal of Contaminant Hydrology, this issue.

Wu, Y. -S., 2000. UZ Flow Models and Submodels. MDL-NBS-HS-000006 REV 00. CRWMS M\&O, Las Vegas, Nevada 


\section{LIST OF FIGURES}

Figure 1. Grid and boundary conditions.

Figure 2. Comparison of Philip et al. (1989) solution with TOUGH2, (a) $s=8$; (b); $s=0.25$.

Figure 3. Fracture and matrix vertical flux and saturation contours using mountain-scale property set (a) matrix saturation; (b) fracture saturation; (c) matrix flux; (d); fracture flux.

Figure 4. Fracture and matrix vertical flux and saturation contours using drift-scale property set and $\gamma=0.41$ (a) matrix saturation; (b) fracture saturation; (c) matrix flux; (d); fracture flux.

Figure 5. Matrix saturation contours using different property sets (a) mountain-scale;(b) driftscale, $\gamma=0.41$; (c) drift-scale, $\gamma=0.61$; (d); drift-scale, $\gamma=0.81$.

Figure 6. Breakthrough curves for drift shadow transport. (a) total percolation flux $=10 \mathrm{~mm} / \mathrm{yr}$, matrix percolation flux $=0.15 \mathrm{~mm} / \mathrm{yr}$; (b) total percolation flux $=10 \mathrm{~mm} / \mathrm{yr}$, matrix percolation flux $=0.85 \mathrm{~mm} / \mathrm{yr}$; (c) total percolation flux $=100 \mathrm{~mm} / \mathrm{yr}$, matrix percolation flux $=0.45 \mathrm{~mm} / \mathrm{yr}$; (d) total percolation flux $=100 \mathrm{~mm} / \mathrm{yr}$, matrix percolation flux $=1.6 \mathrm{~mm} / \mathrm{yr}$.

Figure 7. Contours for Technetium concentration and vertical flux in matrix and fractures at 2535 years. (a) matrix concentration; (b) matrix flux; (c) fracture concentration; (d) fracture flux.

Figure 8. Technetium transport as a function of total percolation flux and matrix percolation flux.

Figure 9. Sensitivity calculations comparing drift shadow transport with transport in unperturbed flow field. (a) total percolation flux $=10 \mathrm{~mm} / \mathrm{yr}$, matrix percolation flux $=0.85 \mathrm{~mm} / \mathrm{yr}$; (b) total percolation flux $=100 \mathrm{~mm} / \mathrm{yr}$, matrix percolation flux $=1.6 \mathrm{~mm} / \mathrm{yr}$. 
Figure 10. Sensitivity calculation for Technetium transport using different values of $\gamma$. 


\section{LIST OF TABLES}

Table 1. Hydrogeologic Model Parameters for the tsw35.

Table 2. Flow Rates Investigated.

Table 3. Transport Coefficients.

Table 4. Advective Transport Times and Computed Transport Times. 


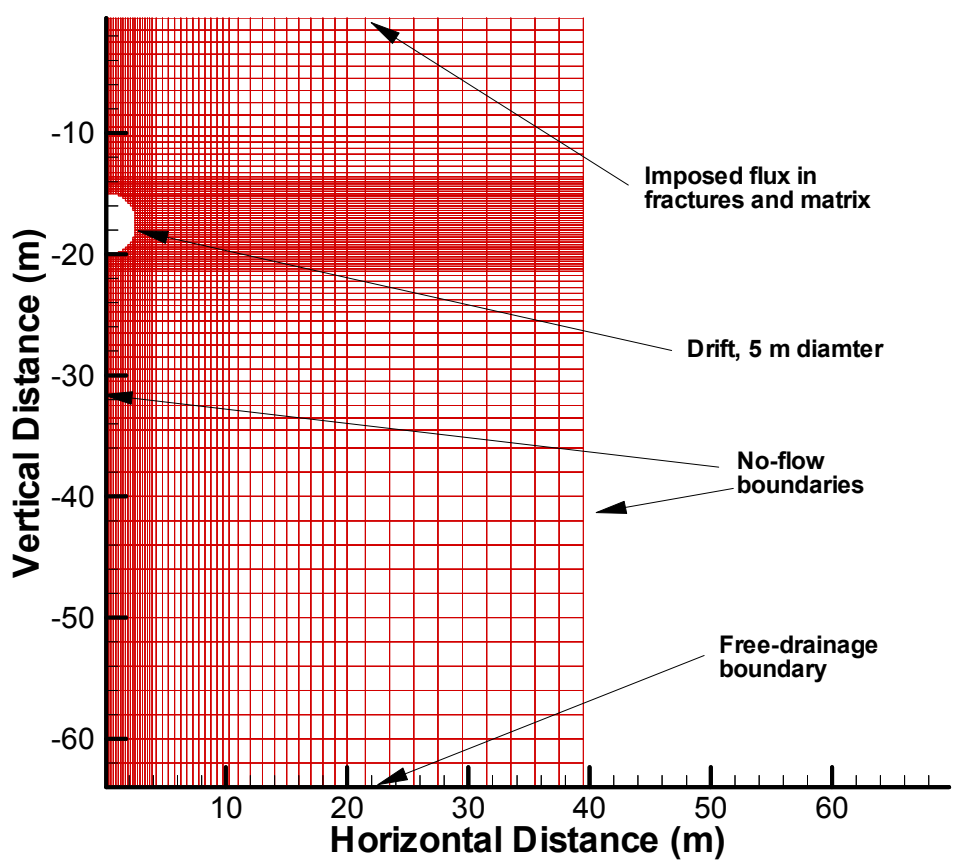

Figure 1. Grid and boundary conditions 


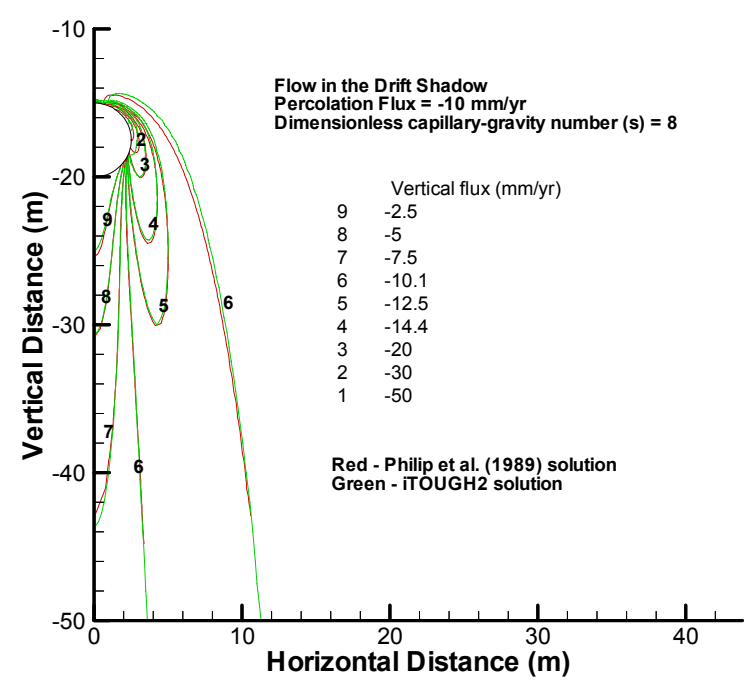

(a)

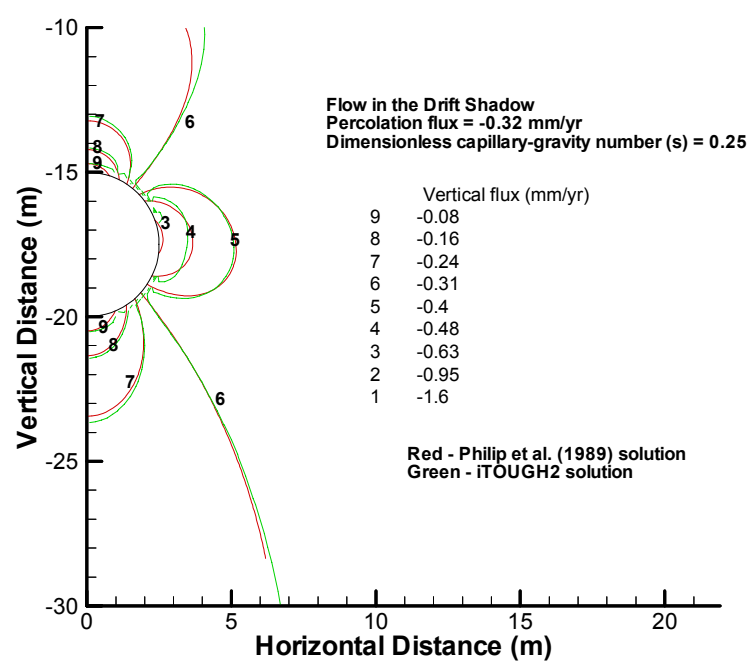

(b)

Figure 2. Comparison of Philip et al. (1989) solution with TOUGH2, (a) $s=8$; (b); $s=0.25$ 


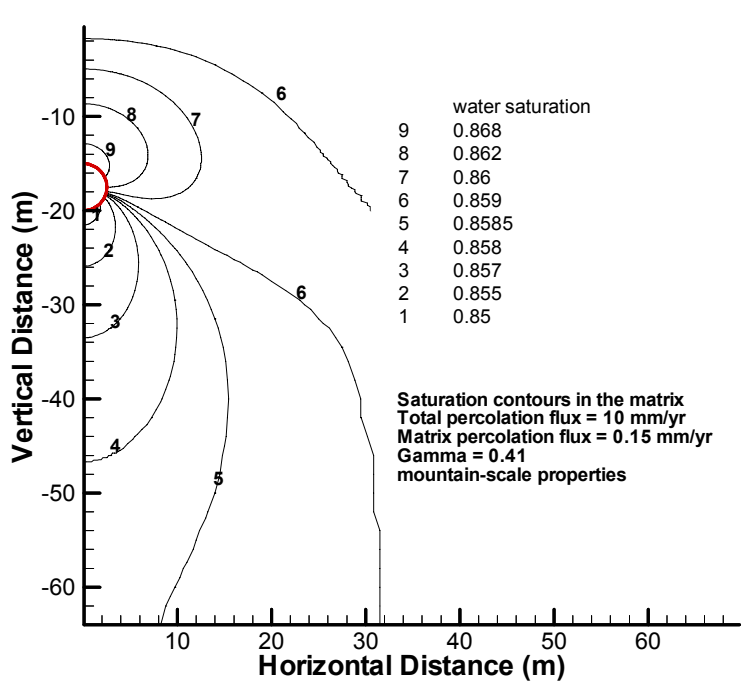

(a)

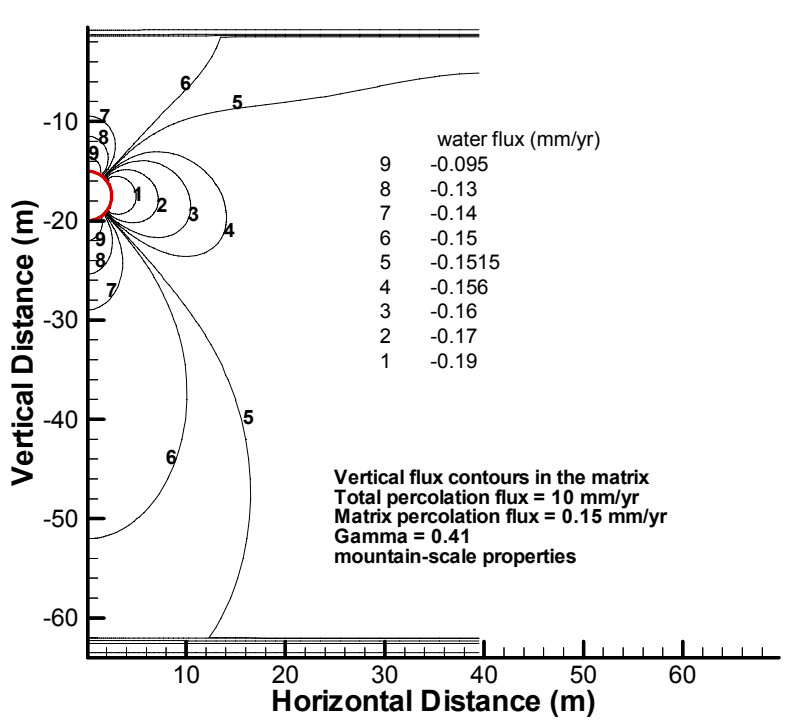

(c)

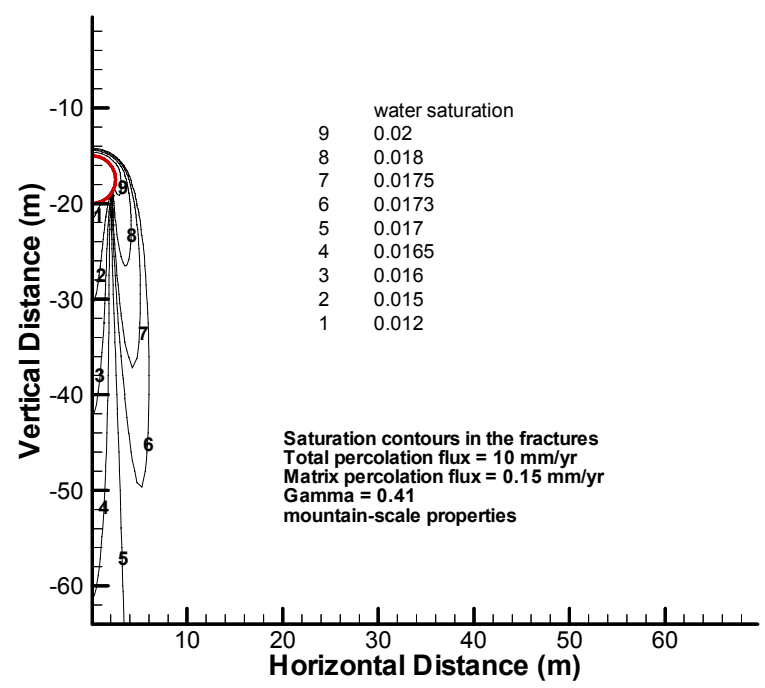

(b)

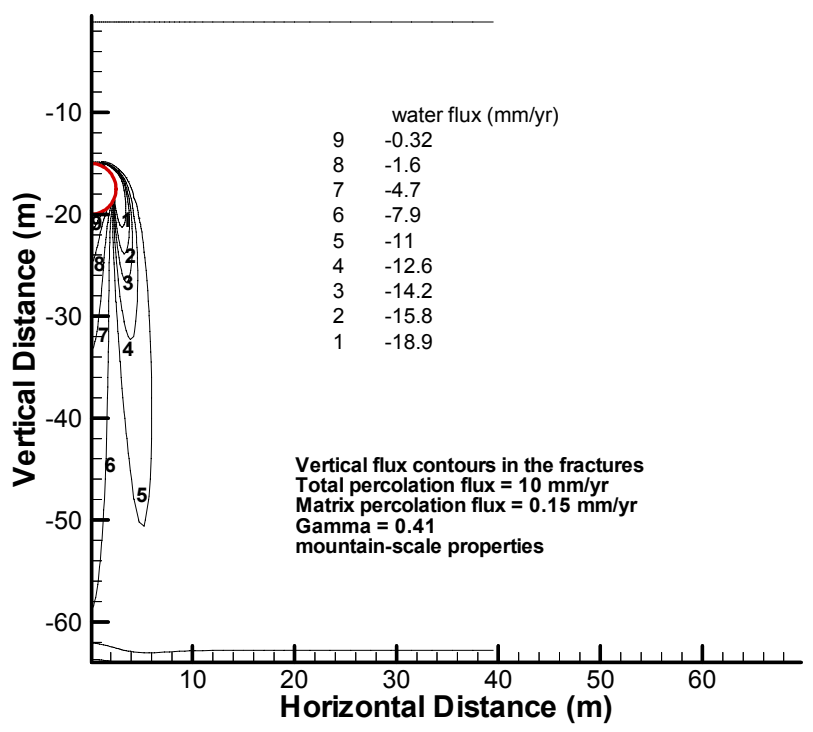

(d)

Figure 3. Fracture and matrix vertical flux and saturation contours using mountain-scale property set (a) matrix saturation; (b) fracture saturation; (c) matrix flux; (d); fracture flux 


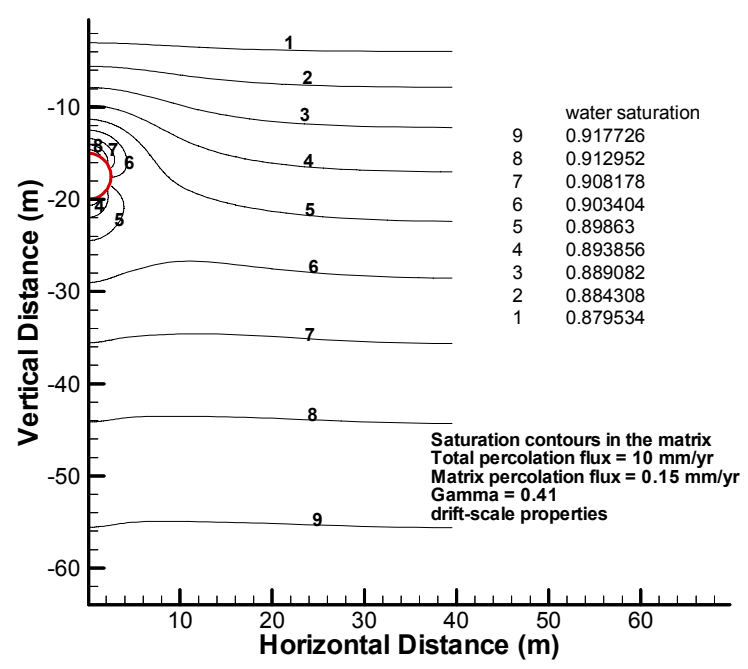

(a)

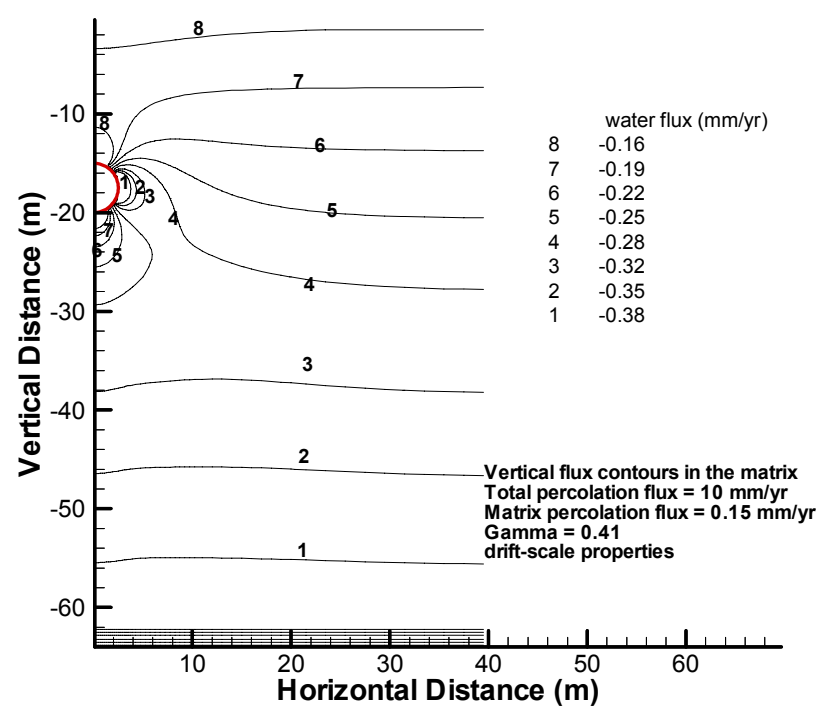

(c)

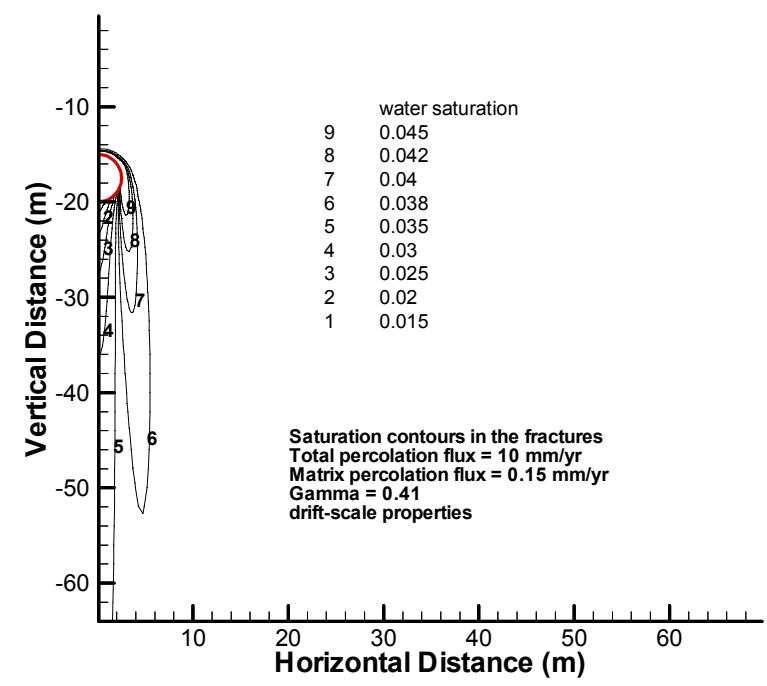

(b)

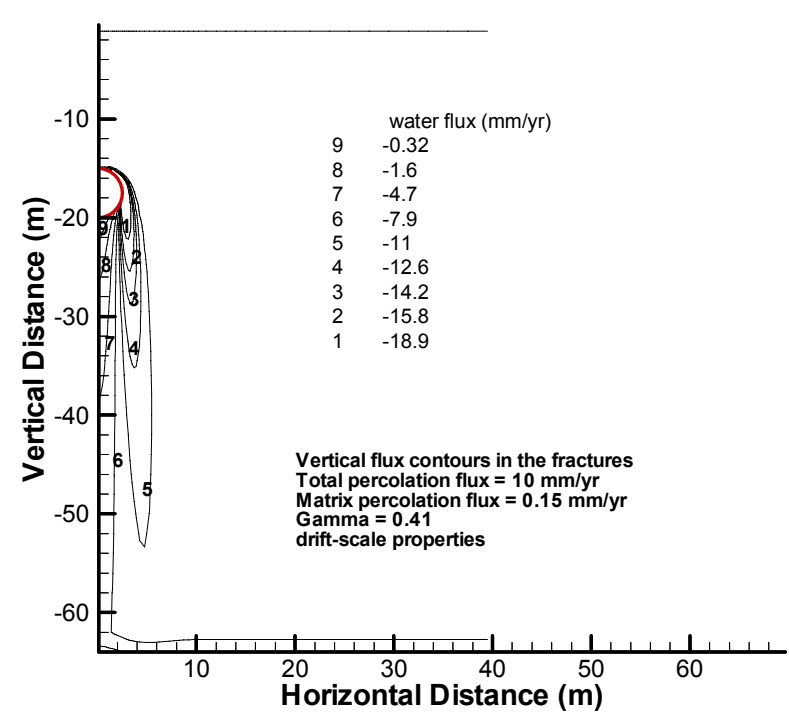

(d)

Figure 4. Fracture and matrix vertical flux and saturation contours using drift-scale property set and $\gamma=0.41$ (a) matrix saturation; (b) fracture saturation; (c) matrix flux; (d); fracture flux 


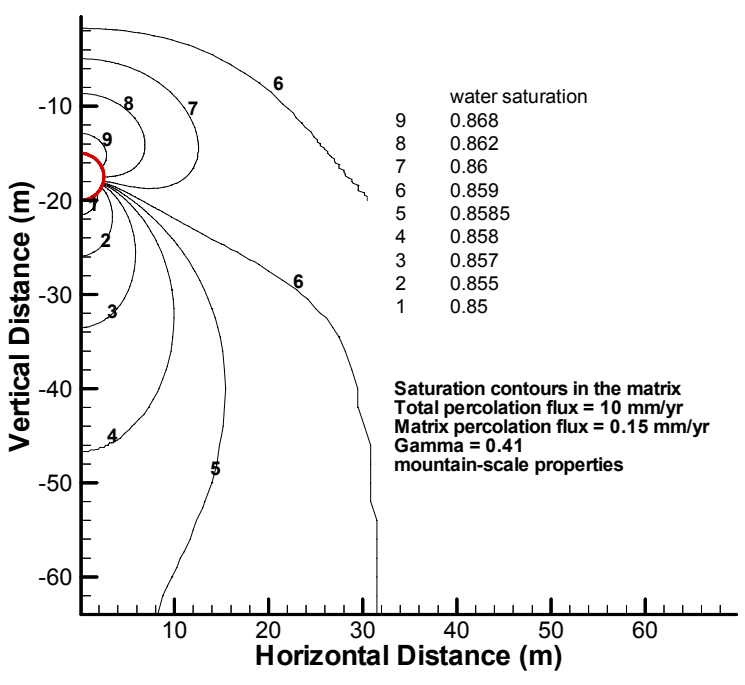

(a)

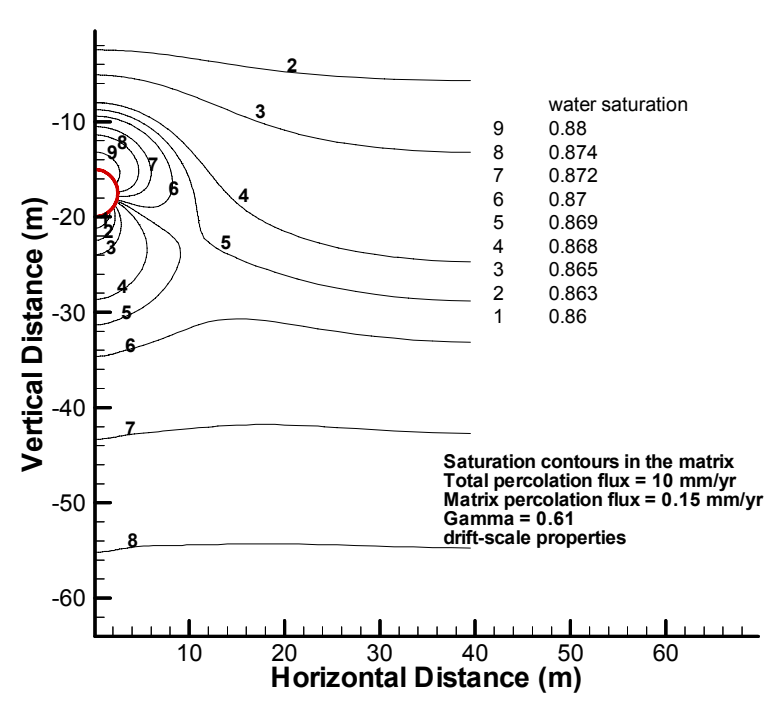

(c)

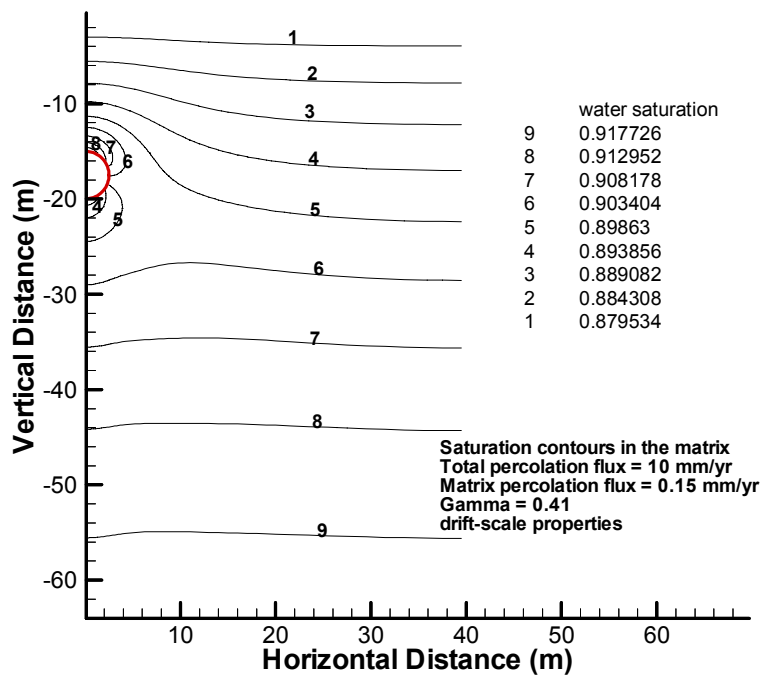

(b)

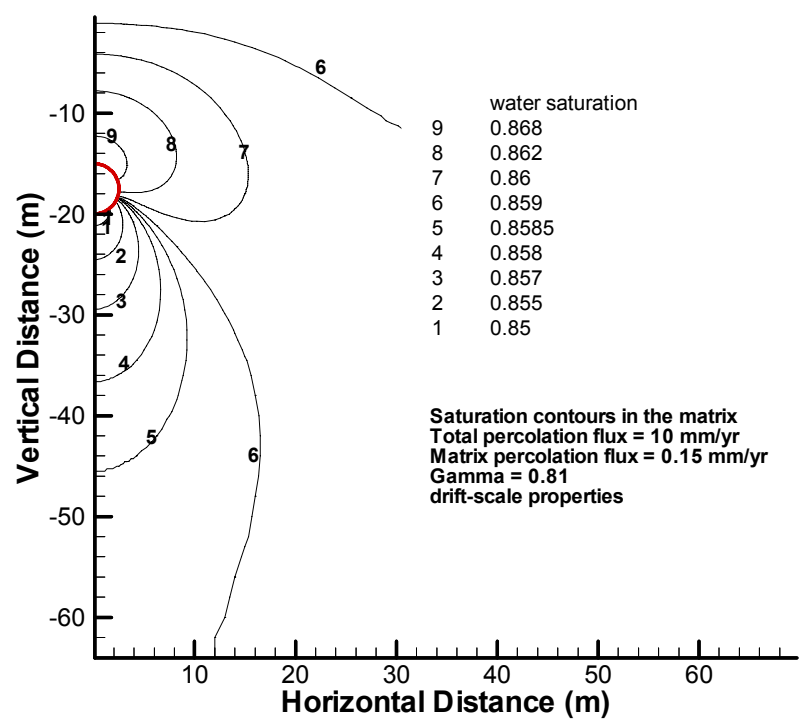

(d)

Figure 5. Matrix saturation contours using different property sets (a) mountain-scale;(b) drift-scale, $\gamma=0.41$; (c) drift-scale, $\gamma=0.61$; (d); drift-scale, $\gamma=0.81$ 


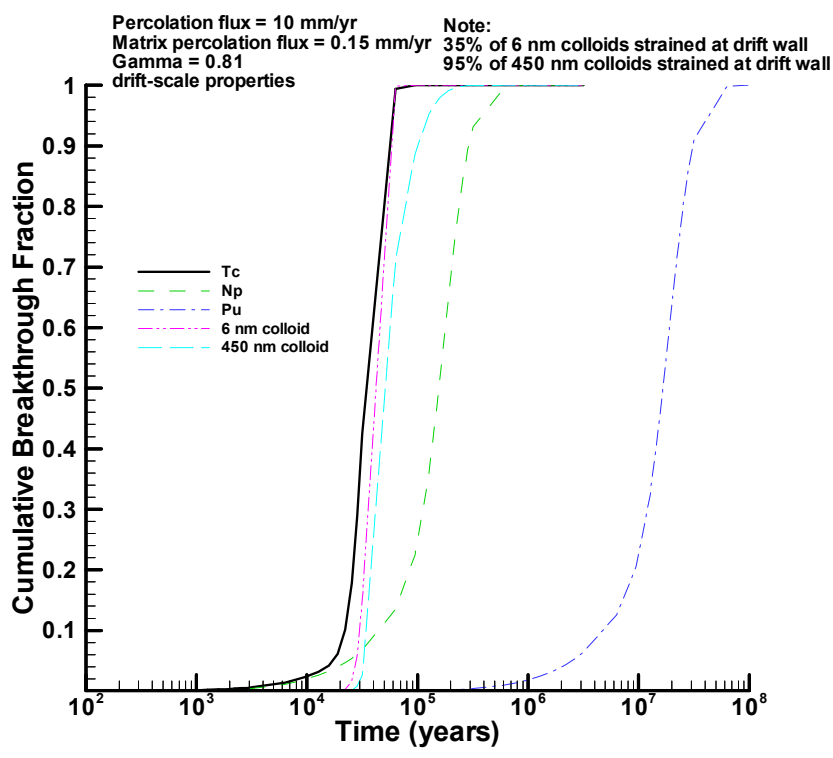

(a)

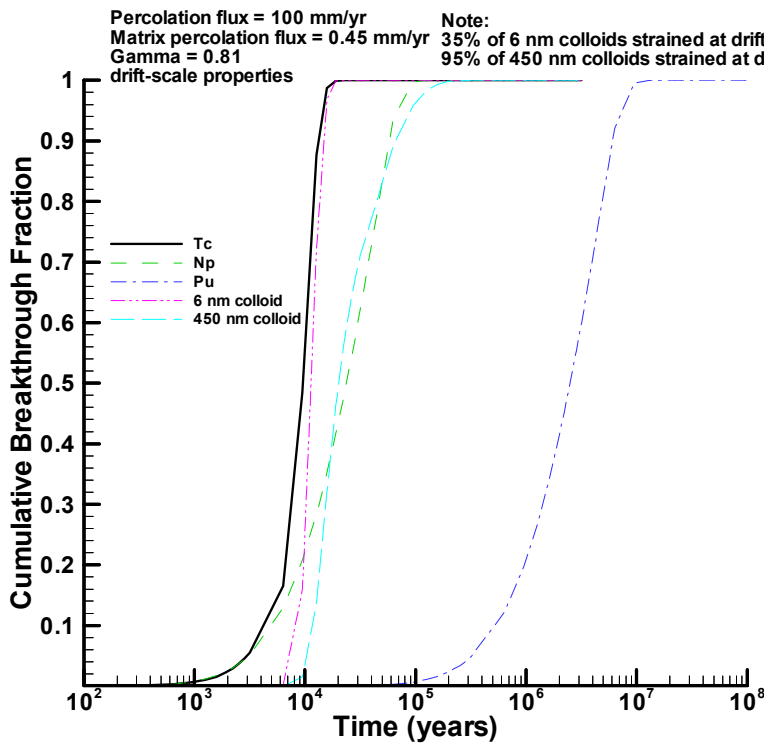

(c)

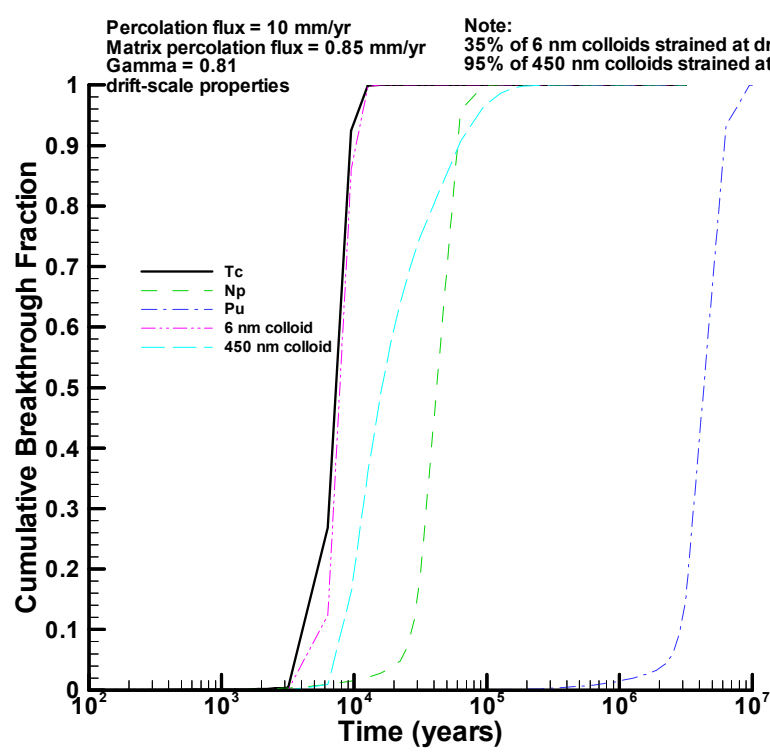

(b)

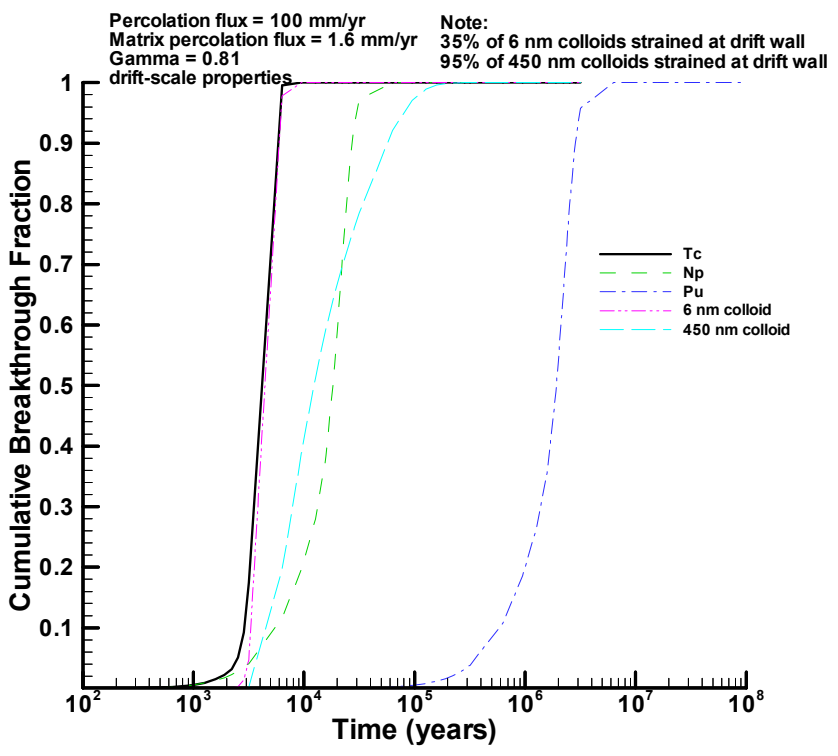

(d)

Figure 6. Breakthrough curves for drift shadow transport. (a) total percolation flux $=10$ $\mathrm{mm} / \mathrm{yr}$, matrix percolation flux $=0.15 \mathrm{~mm} / \mathrm{yr}$; (b) total percolation flux $=10 \mathrm{~mm} / \mathrm{yr}$, matrix percolation flux $=0.85 \mathrm{~mm} / \mathrm{yr}$; (c) total percolation flux $=100 \mathrm{~mm} / \mathrm{yr}$, matrix percolation flux $=0.45 \mathrm{~mm} / \mathrm{yr}$; (d) total percolation flux $=100 \mathrm{~mm} / \mathrm{yr}$, matrix percolation flux $=1.6$ $\mathbf{m m} / \mathbf{y r}$ 


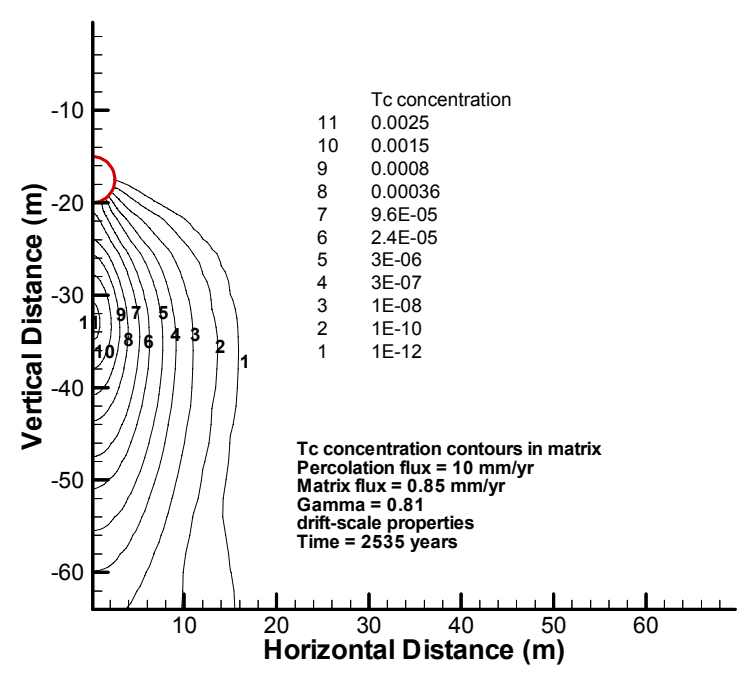

(a)

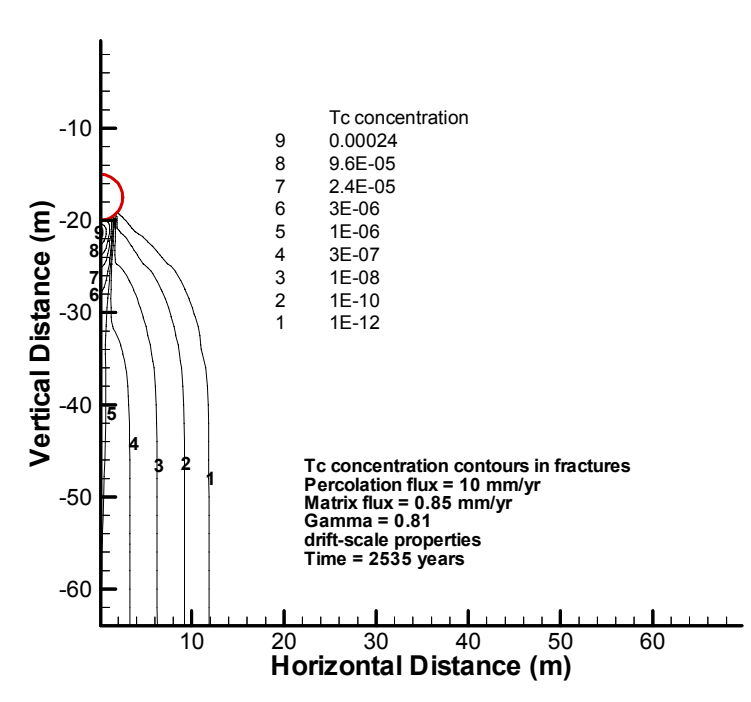

(c)

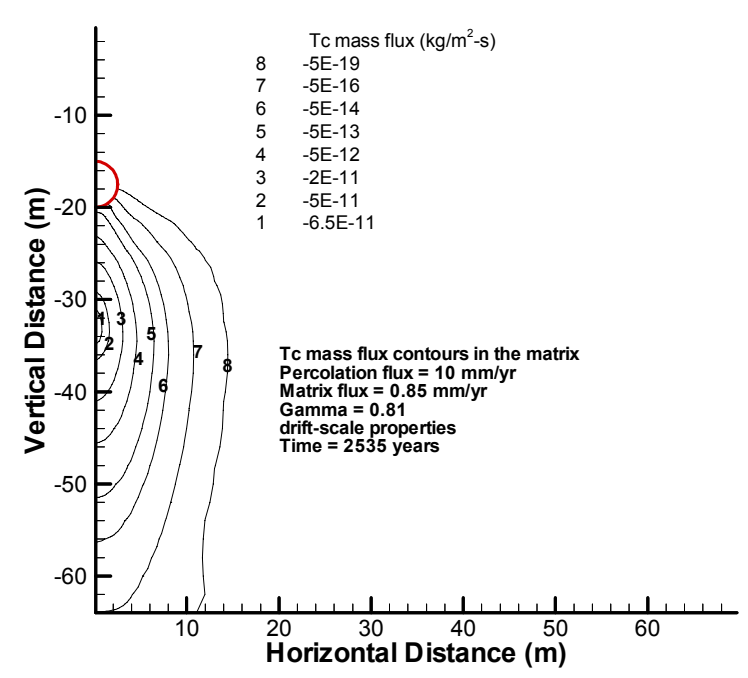

(b)

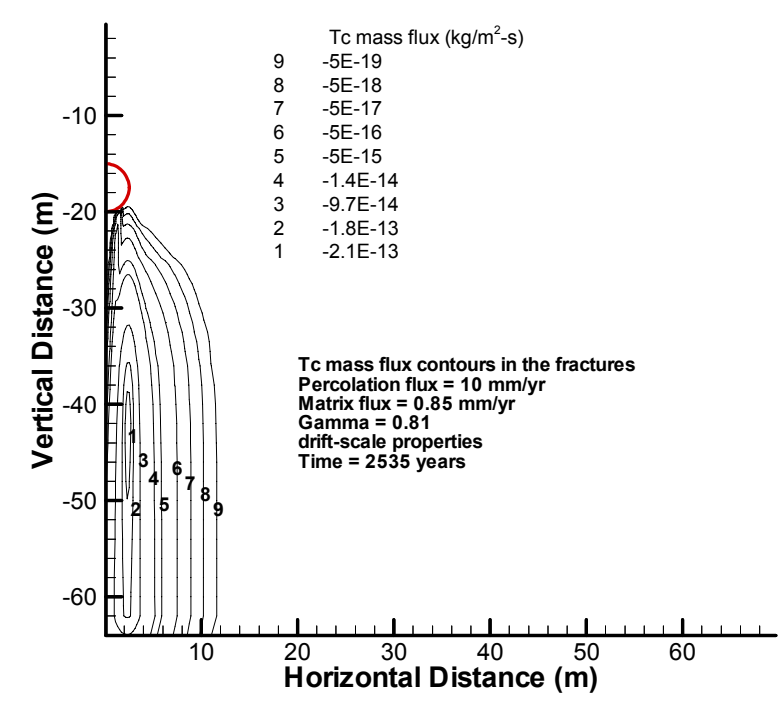

(d)

Figure 7. Contours for Technetium concentration and vertical flux in matrix and fractures at 2535 years. (a) matrix concentration; (b) matrix flux; (c) fracture concentration; (d) fracture flux. 


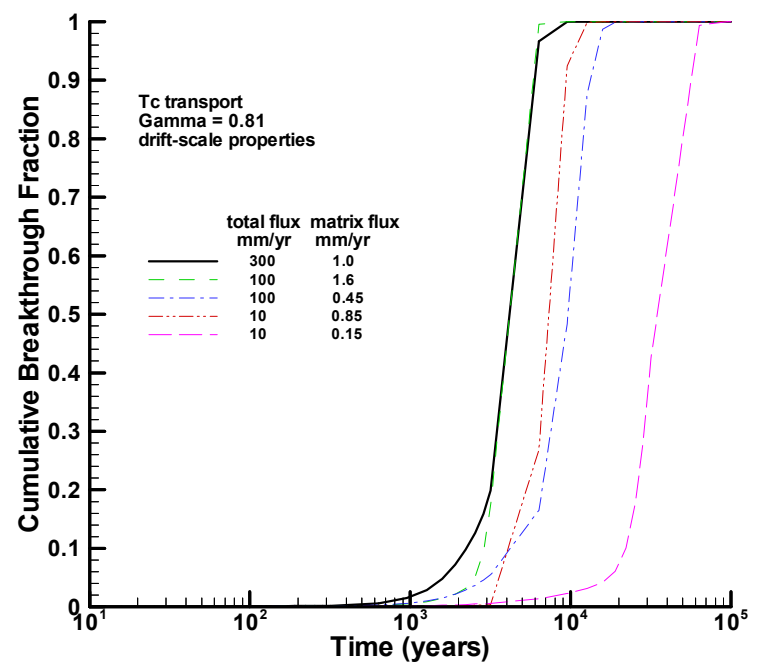

Figure 8. Technetium transport as a function of total percolation flux and matrix percolation flux 


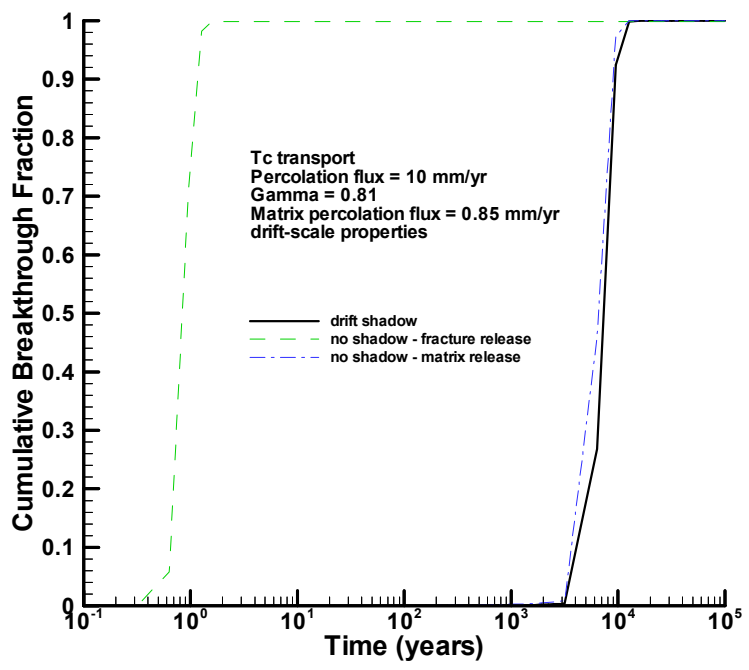

(a)

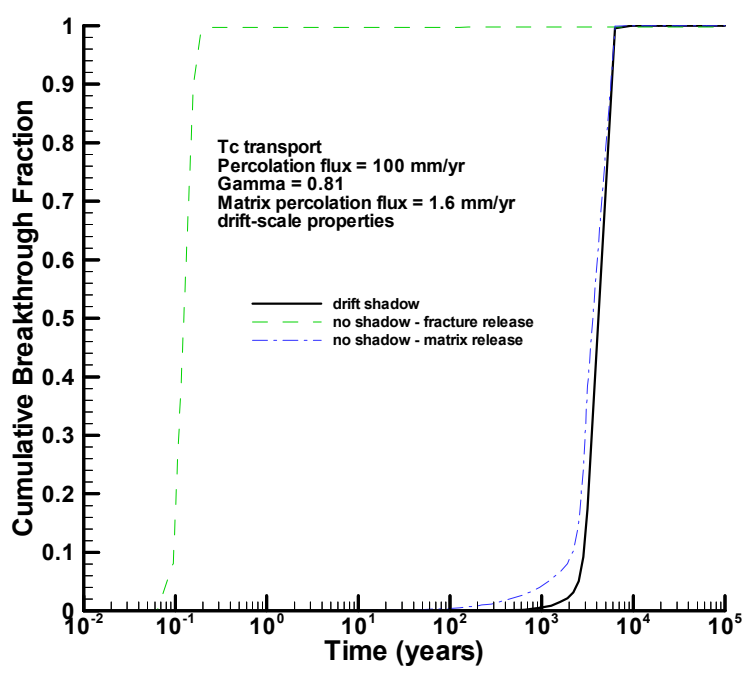

(b)

Figure 9. Sensitivity calculations comparing drift shadow transport with transport in unperturbed flow field. (a) total percolation flux $=10 \mathrm{~mm} / \mathrm{yr}$, matrix percolation flux $=$ $0.85 \mathrm{~mm} / \mathrm{yr}$; (b) total percolation flux $=100 \mathrm{~mm} / \mathrm{yr}$, matrix percolation flux $=1.6 \mathrm{~mm} / \mathrm{yr}$ 


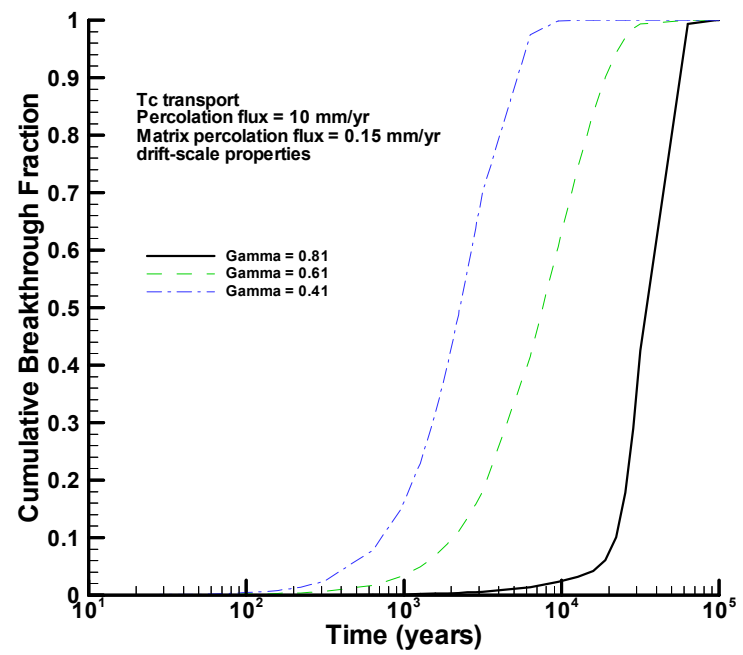

Figure 10. Sensitivity calculation for Technetium transport using different values of $\gamma$. 
Table 1. Hydrogeologic Model Parameters for the tsw35

\begin{tabular}{|l|l|l|l|l|l|l|}
\hline & $\begin{array}{l}\text { Permeability } \\
\left(\mathbf{m}^{\mathbf{2}}\right)\end{array}$ & Porosity & $\begin{array}{l}\text { van Genuchten } \\
\mathbf{a}\left(\mathbf{P a}^{-1}\right)\end{array}$ & $\begin{array}{l}\text { van Genuchten } \\
\mathbf{m}\end{array}$ & $\begin{array}{l}\text { Residual } \\
\text { saturation }\end{array}$ & $\begin{array}{l}\text { Active } \\
\text { fracture } \\
\text { parameter } \\
\gamma\end{array}$ \\
\hline $\begin{array}{l}\text { Matrix } \\
\text { properties }\end{array}$ & $3.04 \times 10^{-17}$ & 0.131 & $6.44 \times 10^{-6}$ & 0.236 & 0.12 & N/A \\
\hline $\begin{array}{l}\text { Mountain- } \\
\text { scale fracture } \\
\text { properties }\end{array}$ & $4.51 \times 10^{-11}$ & 0.015 & $7.39 \times 10^{-4}$ & 0.611 & 0.01 & 0.41 \\
\hline $\begin{array}{l}\text { Modified } \\
\text { drift-scale } \\
\text { fracture } \\
\text { properties }\end{array}$ & $1.29 \times 10^{-12}$ & 0.015 & $7.39 \times 10^{-4}$ & 0.611 & 0.01 & 0.81 \\
\hline
\end{tabular}


Table 2. Flow Rates Investigated

\begin{tabular}{|l|l|l|}
\hline Total Flow Rate (mm/yr) & Fracture Flow Rate (mm/yr) & Matrix Flow Rate (mm/yr) \\
\hline 10 & 9.85 & 0.15 \\
\hline 10 & 9.15 & 0.85 \\
\hline 100 & & 0.45 \\
\hline 100 & 99.55 & 1.6 \\
\hline 300 & 98.4 & 1.0 \\
\hline
\end{tabular}


Table 3. Transport Coefficients

\begin{tabular}{|c|c|c|c|c|c|c|}
\hline & \multicolumn{3}{|l|}{ Matrix } & \multicolumn{3}{|l|}{ Fractures } \\
\hline & $\begin{array}{l}\text { Diffusion } \\
\text { Coefficient } \\
\left(\mathrm{m}^{2} / \mathrm{s}\right)\end{array}$ & Tortuosity & $\begin{array}{l}\text { Sorption } \\
\text { Coefficient } \\
\left(\mathrm{m}^{3} / \mathrm{kg}\right)\end{array}$ & $\begin{array}{l}\text { Diffusion } \\
\text { Coefficient } \\
\left(\mathrm{m}^{2} / \mathrm{s}\right)\end{array}$ & Tortuosity & $\begin{array}{l}\text { Sorption } \\
\text { Coefficient } \\
\left(\mathrm{m}^{3} / \mathrm{kg}\right)\end{array}$ \\
\hline Technetium & $1.6 \times 10^{-9}$ & 0.02 & 0 & $1.6 \times 10^{-9}$ & 0.015 & 0 \\
\hline Neptunium & $1.6 \times 10^{-9}$ & 0.1 & $3.0 \times 10^{-4}$ & $1.6 \times 10^{-9}$ & 0.015 & 0 \\
\hline Plutonium & $1.6 \times 10^{-9}$ & 0.1 & $3.75 \times 10^{-2}$ & $1.6 \times 10^{-9}$ & 0.015 & 0 \\
\hline $\begin{array}{l}\text { Colloid } \\
6 \mathrm{~nm}\end{array}$ & $7.15 \times 10^{-11}$ & 0.02 & 0 & $7.15 \times 10^{-11}$ & 0.015 & 0 \\
\hline $\begin{array}{l}\text { Colloid } \\
450 \mathrm{~nm}\end{array}$ & $9.53 \times 10^{-13}$ & 0.02 & 0 & $9.53 \times 10^{-13}$ & 0.015 & 0 \\
\hline
\end{tabular}


Table 4. Advective Transport Times and Computed Transport Times

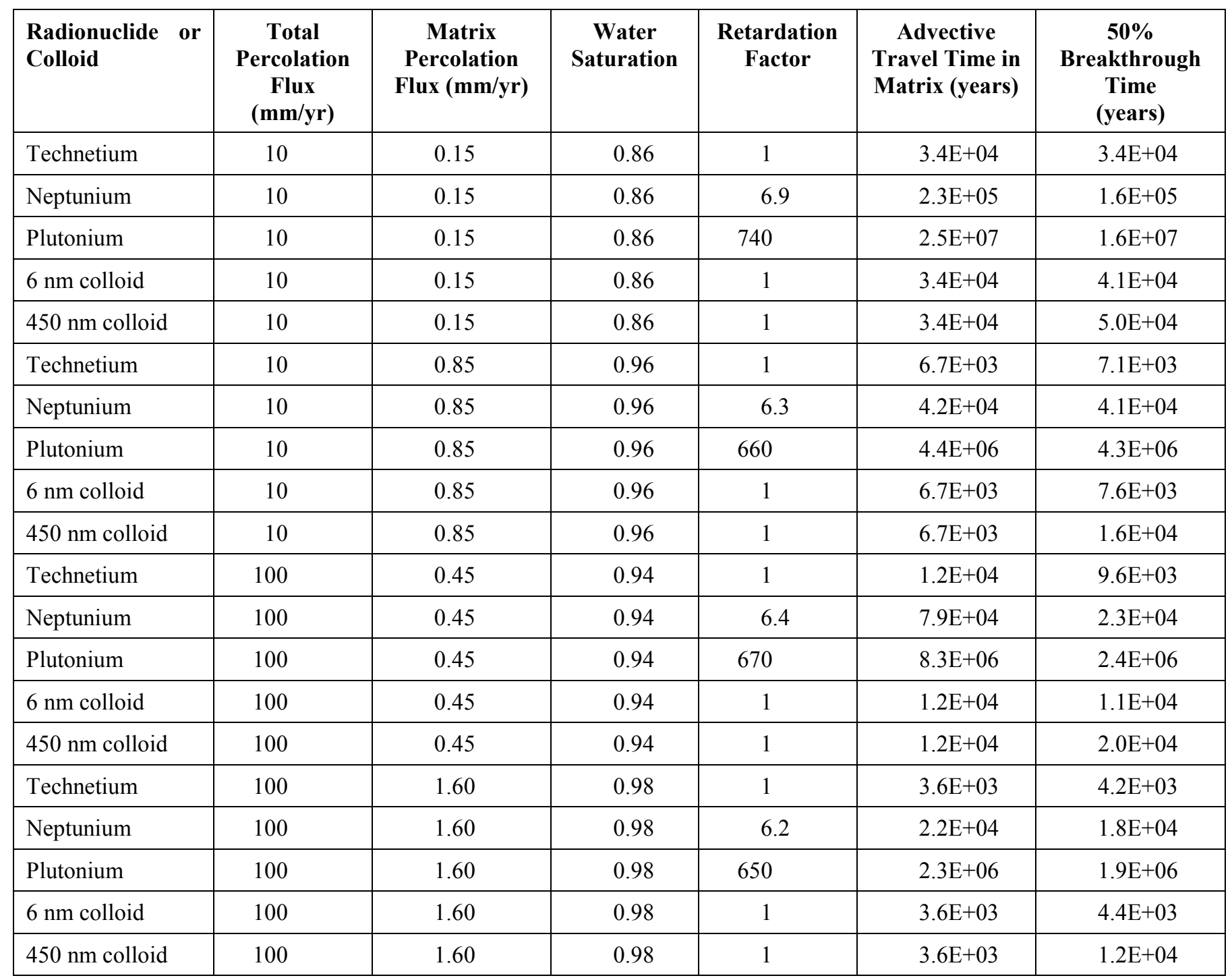

